\title{
Clear Cell Carcinoma of the Liver: A Comparative Immunohistochemical Study with Renal Clear Cell Carcinoma
}

\author{
Linda A. Murakata, M.D., Kamal G. Ishak, M.D., Ph.D., Ugochukwu C. Nzeako, M.D. \\ Armed Forces Institute of Pathology, Washington, DC
}

\begin{abstract}
Morphologic differentiation of clear cell hepatocellular carcinoma (HCC-CC) from clear cell renal carcinoma (RCC-CC) may not be possible without the aid of immunohistochemical stains. We performed a battery of immunohistochemical stains on 10 previously diagnosed HCC-CCs, and 10 RCC-CCs, in order to determine which single or combination of immunostains would be most useful in diagnosis. We concluded that a positive Hepatocyte immunostain (DAKO) is sufficient for a diagnosis of HCC-CC if enough tissue is available. This immunostain distinguishes HCC-CC from other clear cell malignancies with sensitivity of $90 \%$ and specificity of $100 \%$, when biopsy material is adequate. Other tests were much less sensitive, although several had specificity of $100 \%$. A negative immunostain does not exclude the diagnosis of HCC-CC (negative predictive value $91 \%$, especially in small biopsy material) and should be followed by additional immunostains such as pCEA for demonstration of tumor canaliculi, ubiquitin for Mallory bodies, and several epithelial cell markers that are typically positive in RCC-CC (epithelial membrane antigen, Leu M-1, pancytokeratin) and negative in HCC-CC.
\end{abstract}

KEY WORDS: Clear cell carcinoma, Hepatocyte, HepPar 1, Kidney, Liver.

Mod Pathol 2000;13(8):874-881

The clear cell variant of hepatocellular carcinoma (HCC-CC) is often histologically indistinguishable from metastatic renal clear cell carcinoma (RCCCC). They are partially or completely encapsulated, with occasional hemorrhage and necrosis. Both contain large, water-clear cells arranged in acinar,

Copyright () 2000 by The United States and Canadian Academy of Pathology, Inc.

VOL. 13, NO. 8, P. 874, 2000 Printed in the U.S.A.

Date of acceptance: March 1, 2000.

Address reprint requests to: Linda A. Murakata, M.D., Armed Forces Institute of Pathology, Department of Hepatic \& Gastrointestinal Pathology, Division of Hepatic Pathology, Room 3107, Washington, DC 203066000; e-mail: murakata@afip.osd.mil; fax: 202-782-4694. trabecular or solid patterns, and both lack intratumoral fibrosis (except in areas of hemorrhage and necrosis).

Until recently, our work-up to differentiate metastatic carcinoma from hepatocellular carcinoma (HCC) included a panel of histochemical and immunohistochemical stains. If foci of classical trabecular hepatocellular carcinoma are present, a panel is not necessary. The panel included digested periodic acid-Schiff stain, mucicarmine, polyclonal carcinoembryonic antigen (pCEA), epithelial membrane antigen (EMA), BER-EP4, and Kermix (AE1/ $\mathrm{AE} 3 / \mathrm{CK} 1)$. A clinical history of a renal mass is helpful, but does not exclude the possibility of two primary tumors. Commercial availability of a hepatocyte monoclonal antibody (Hepatocyte clone OCH1E5.2.10, DAKO, Denmark) suggested the possibility of eliminating the need for additional costly immunohistochemical stains. In this study, we evaluated the Hepatocyte antibody (DAKO) on 10 previously diagnosed RCC-CCs, 10 HCC-CCs, and 11 clear cell tumors from other organs. In addition, a panel of 12 other immunohistochemical stains was evaluated on the HCC-CC and RCC-CC.

\section{MATERIALS AND METHODS}

The files of the Armed Forces Institute of Pathology, Washington DC, were searched for clear cell tumors of liver and kidney. Ten examples of each tumor were selected if the tumor was unequivocally primary in that organ, and if the paraffin block was available with sufficient tissue for recuts. Also, 11 clear cell tumors from other organs, three salivary gland (one mucoepidermal carcinoma, clear cell type; two clear cell adenocarcinomas), three lung (three poorly differentiated squamous cell carcinomas with clear cell features), two thyroid gland (two follicular carcinomas with clear cells), two ovary (two clear cell carcinomas), and one urinary bladder (one transitional cell carcinoma with clear cell features) were retrieved using the same criteria. 
All hematoxylin-eosin-stained sections were reviewed. Additional sections were obtained from the paraffin blocks for special stains and immunohistochemistry. Histochemical stains performed included mucicarmine, periodic acid Schiff (periodic acid-Schiff) with and without diastase, reticulin, and Hall's stain for bilirubin.

Immunohistochemical staining was performed after sections were deparaffinized using primary antisera for anti-human Hepatocyte (DAKO), Kermix (AE1/AE3/CK1), CK7, CK20, polyclonal carcinoembryonic antigen (pCEA), alpha-fetoprotein (AFP), S-100, epithelial membrane antigen (EMA), BER-EP4, chromogranin, synaptophysin, ubiquitin, and Leu $\mathrm{M}-1$. The antibodies, their sources, and the dilutions for each are listed in Table 1. When required, sections were pretreated enzymatically with $0.05 \%$ Sigma VIII protease for $3 \mathrm{~min}$ at $37^{\circ} \mathrm{C}$. This was followed by rinsing the secondary antibody, rinsing again, and applying avidin biotin complex (supplied in kit form, Vectastain kit, Vector Labs Inc., Burlingham, CA). The slides were counterstained with Gill's hematoxylin and coverslipped. Appropriate tissues were used as positive controls and non-immune rabbit or mouse sera were substituted for the primary antibody for negative controls.

\section{RESULTS}

\section{Hepatocellular Carcinoma}

Microscopically, all cases of HCC-CC showed moderate-to-marked cytoplasmic accumulation of glycogen and/or macro- and microvesicular intracytoplasmic fat droplets that dissolved during processing, leaving behind a "clear" cytoplasm. The tumor growth patterns ranged from sheets of cells to trabeculae with or without pseudoglands, or a combination of patterns (Fig. 1). Foci of classical trabecular HCC were seen in $60 \%$ of the cases admixed with sheets of clear tumor cells (Table 2 and

TABLE 1. Summary of Antibodies Used

\begin{tabular}{lllc}
\hline \multicolumn{1}{c}{ Antibody } & \multicolumn{1}{c}{ Type } & Dilution & Source \\
\hline Hepatocyte (OCH1E5) & Monoclonal & $1: 80$ & DAKO \\
Kermix (AE1/AE3/CK1) & Monoclonal & $1: 200$ & DAKO, Hybritech \\
CK7 & Monoclonal & $1: 40$ & DAKO \\
CK20 & Monoclonal & $1: 80$ & DAKO \\
CEA & Polyclonal & $1: 400$ & DAKO \\
BER-EP4 & Monoclonal & $1: 100$ & DAKO \\
EMA & Monoclonal & $1: 200$ & DAKO \\
S-100 & Polyclonal & $1: 800$ & DAKO \\
AFP & Polyclonal & $1: 160$ & DAKO \\
Chromogranin & Polyclonal & $1: 1600$ & Boehringer-Mann \\
Synaptophysin & Polyclonal & $1: 40$ & Boehringer-Mann \\
Ubiquitin & Polyclonal & $1: 200$ & DAKO \\
Leu M-1 (CD15) & Monoclonal & $1: 5000$ & Ventana \\
\hline
\end{tabular}

CK, cytokeratin; CEA, carcinoembryonic antigen; EMA, epithelial membrane antigen; AFP, alpha-fetoprotein.

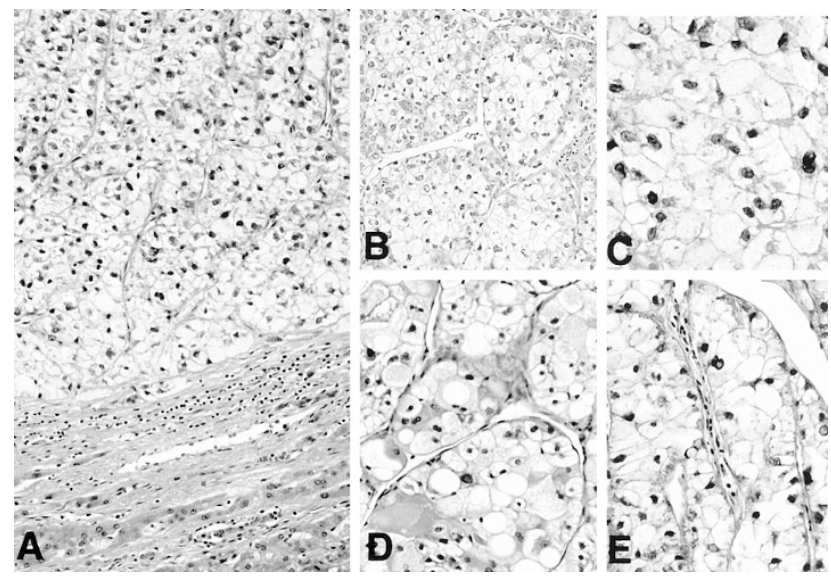

FIGURE 1. Hepatocellular clear cell carcinoma. A, low-power view of tumor, capsule, and normal nontumor parenchyma. B, medium-power view, macrotrabeculae. C, high-power view, sheets of tumor cells. D and E, high-power views, macrotrabeculae, sinusoids.

TABLE 2. Histologic Features of Hepatocellular Clear Cell Carcinoma

\begin{tabular}{rrrrrrc}
\hline Case & $\begin{array}{c}\text { Classic } \\
\text { HCC areas }\end{array}$ & $\begin{array}{c}\text { Grade/ } \\
\text { Pattern }\end{array}$ & Capsule & $\begin{array}{c}\text { Hem/ } \\
\text { Necr/ } \\
\text { Fibr }\end{array}$ & MB & $\begin{array}{c}\text { Cirrhosis } \\
\text { in Non- } \\
\text { tumor }\end{array}$ \\
\hline 1 & + & $2 / \mathrm{t} / \mathrm{s}$ & + & $+/+/+$ & 0 & 0 \\
2 & 0 & $3 / \mathrm{t} / \mathrm{s}$ & + & $+/+/+$ & 0 & $\mathrm{NA}$ \\
3 & + & $1 / \mathrm{t} / \mathrm{s}$ & + & $0 /+/+$ & 0 & + (HBV) \\
4 & + & $2 / \mathrm{t} / \mathrm{s} / \mathrm{pg}$ & + & $+/+/+$ & + & $+/-$ \\
5 & + & $4 / \mathrm{t} / \mathrm{s}$ & + & $+/+/+$ & 0 & 0 \\
6 & 0 & $1 / \mathrm{t} / \mathrm{s}$ & + & $+/+/+$ & + & 0 \\
7 & 0 & $1 / \mathrm{s}$ & + & $0 / 0 / 0$ & + & 0 (fat) \\
8 & + & $1 / \mathrm{t} / \mathrm{s}$ & + & $0 / 0 /+$ & + & 0 \\
9 & + & $1 / \mathrm{t}$ & + & $+/+/+$ & 0 & 0 (iron) \\
10 & 0 & $1 / \mathrm{t} / \mathrm{s}$ & $+/-$ & $+/+/+$ & 0 & 0
\end{tabular}

+ , present; 0, not present; NA, not available; t, trabecular; s, solid; pg, pseudoglandular; Hem, hemorrhage; Necr, necrosis; Fibr, fibrosis; MB, Mallory bodies.

Fig. 2). Except for the capsule, fibrosis was rare unless previous necrosis or hemorrhage had occurred. Tumor canaliculi were often difficult to see in HE sections but were identified in $60 \%$ of our cases with the use of a polyclonal CEA immunostain (Table 3 and Fig. 3). Mallory bodies occurred in $40 \%$ of the HCC-CC cases; none were found in the RCC-CC cases (Table 2 and Fig. 3).

The Hepatocyte immunostain (DAKO) in normal hepatic parenchyma showed abundant, darkbrown, coarsely granular staining that was evenly dispersed within the cytoplasm of nearly all hepatocytes (Fig. 4) (1-3). Some of the larger granules had an outer dense staining "shell" and a clear center. In fatty livers, the reaction product was less prominent and patchy due to displacement of organelles by the fat vacuoles. The same was true of HCC-CC where the reactivity was patchy and variable, showing scattered positive cells with a few granules, to foci with strong, diffuse staining of many cells (Fig. 4).

The immunohistochemical reactivity of HCC-CC to a panel of antibodies is listed in Table 3. The 


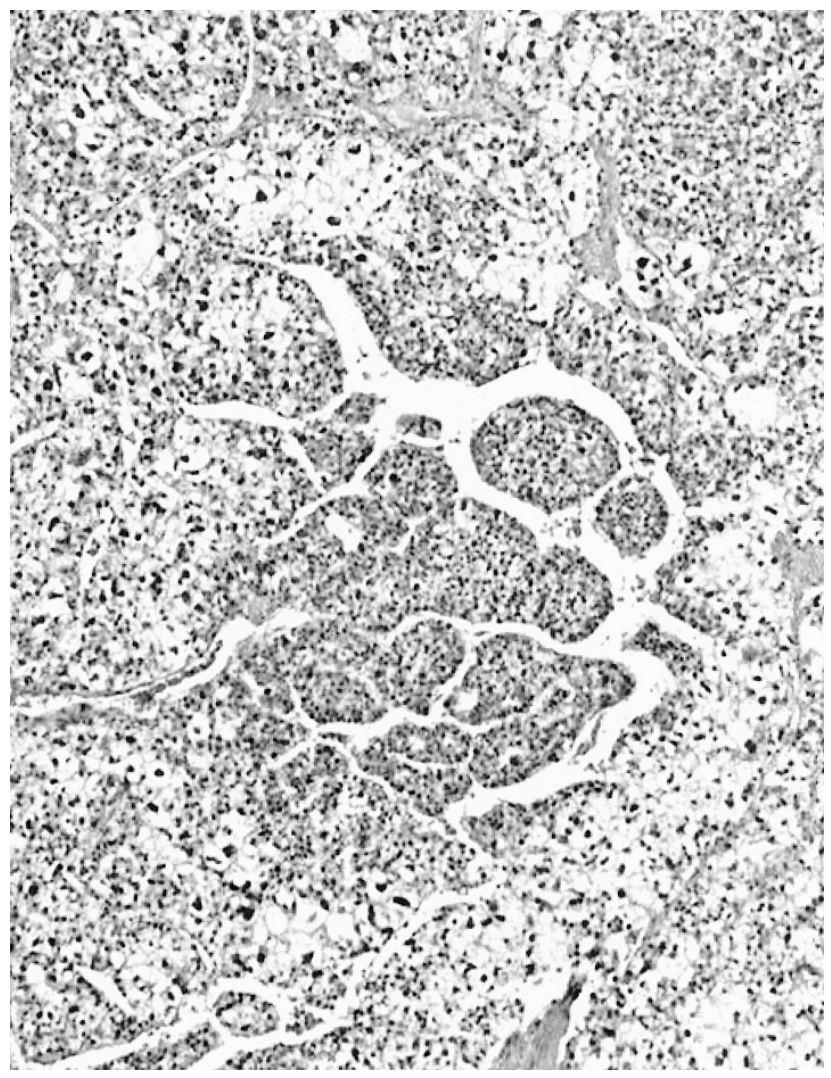

FIGURE 2. Hepatocellular clear cell carcinoma. Focus of classical trabecular HCC (center).

most useful positive stains were the Hepatocyte antibody (DAKO) and the pCEA, which demonstrates canaliculi in tumor and nontumor liver by cross-reacting with biliary glycoproteins (Fig. 3). Both stains were patchy in distribution so that false-negative staining could be due to sampling. Patchy reactivity with biliary cytokeratins (CK 7, 19), Kermix (AE1/AE3/CK1), BER-EP4, and cytokeratin 20 (which also reacts with the epithelium of the gallbladder, pancreas, gastrointestinal tract and other carcinomas) was noted in one case, but is not an uncommon finding in HCC or normal liver cells due to biliary/hepatocellular metaplasia or aberrant antigen expression (4). Other immunostains (EMA, S-100, chromogranin, synaptophysin, and Leu $\mathrm{M}-1$ ) listed in Table 3 were negative. Histochemical stains for mucin (mucicarmine, Alcian blue) were negative, focal bile production was noted in one case with Hall's bile stain, and periodic acid-Schiff after digestion was positive for cytoplasmic glycogen.

\section{Clear Cell Renal Carcinoma}

Microscopically and ultrastructurally, this tumor is very similar to HCC-CC, with water-clear cells and sparse organelles (5)(Fig. 5). Varying quantities of cytoplasmic glycogen and lipid were present in all cases (usually mild to moderate amounts on
dPAS). The tumor growth patterns included papillary, alveolar, tubular, and solid sheets (Fig. 5). A fibrous capsule separated the tumor from the renal parenchyma and sometimes contained entrapped glomeruli and renal tubules. Intratumoral fibrosis was rare unless hemorrhage or necrosis had occurred. The immunohistochemical reactivity of RCC-CC, using the identical panel of immunostains for HCC-CC, is listed in Table 4. The EMA, Leu $\mathrm{M}-1$, and Kermix showed patchy, moderately strong cytoplasmic and membranous staining (Fig. 6). The expression of S-100 was very focal, with minimal to mild intensity. The BER-EP4 immunostain was negative in all but two cases, as were the remaining immunostains. Although the Hepatocyte immunostain (DAKO) was nonreactive in the tumor, in several cases, normal renal tubules showed focal, mild positivity, but the staining was homogeneous and fine rather than coarse and granular. Histochemical stains for mucin (mucicarmine, Alcian blue) were negative, Hall's bile stain was negative, and periodic acid-Schiff after digestion was positive for cytoplasmic glycogen.

\section{Miscellaneous Clear Cell Carcinomas}

Eleven clear cell tumors involving the salivary gland (three cases), lung (three cases), thyroid gland (two cases), ovary (two cases), and urinary bladder (one case) were not immunoreactive to the Hepatocyte antibody (DAKO).

\section{Immunostain Sensitivity and Specificity}

Sensitivity and specificity were calculated for all immunostains to evaluate their role in distinguishing HCC-CC from RCC-CC, or vice versa. For identifying HCC-CC, sensitivity and specificity, respectively, were $90 \%$ and $100 \%$ for Hepatocyte (DAKO) (Tables 5 and 6 ), $60 \%$ and $100 \%$ for pCEA, $10 \%$ and $100 \%$ for CK $7,10 \%$ and $100 \%$ for CK $20,10 \%$ and $80 \%$ for BER-EP4, $10 \%$ and $100 \%$ for synaptophysin, $30 \%$ and $100 \%$ for ubiquitin. Chromogranin and alpha-fetoprotein were negative in all HCC-CC and RCC-CC, thus making them completely insensitive for distinguishing one tumor type from another.

Other immunostains were more useful for identifying RCC-CC. For these, sensitivity and specificity, respectively, were $90 \%$ and $100 \%$ for Kermix, $90 \%$ and $100 \%$ for EMA, and $40 \%$ and $100 \%$ for S-100. Although Leu M-1 stains were unavailable for 3 RCC-CC, all the available seven cases showed strong focal staining suggesting both sensitivity and specificity of $100 \%$. The immunostains in this group were negative in all HCC-CC. 
TABLE 3. Immunohistochemical Findings in Hepatocellular Clear Cell Carcinomas

\begin{tabular}{|c|c|c|c|c|c|c|c|c|c|c|c|c|c|}
\hline Case & Hepatocyte & Kermix & CK 7 & $\begin{array}{l}\text { CK } \\
20\end{array}$ & $\begin{array}{c}\text { pCEA } \\
{ }^{*} \text { can }\end{array}$ & AFP & S-100 & EMA & $\begin{array}{c}\text { BER- } \\
\text { EP4 }\end{array}$ & $\mathrm{CHR}$ & SYN & $\begin{array}{l}\text { Leu } \\
\text { M-1 }\end{array}$ & Ubiq \\
\hline 1 & $4+$ & 0 & 0 & 0 & $2+$ & 0 & 0 & 0 & 0 & 0 & 0 & 0 & $\mathrm{~N}$ \\
\hline 2 & $1+\mathrm{f}$ & 0 & 0 & 0 & 0 & 0 & 0 & 0 & 0 & 0 & $3+\mathrm{f}$ & 0 & $\mathrm{~N}$ \\
\hline 3 & $3+$ & 0 & 0 & 0 & $2+$ & 0 & 0 & 0 & 0 & 0 & 0 & 0 & $\mathrm{~N}$ \\
\hline 4 & $1+\mathrm{f}$ & 0 & 0 & 0 & $2+$ & 0 & 0 & 0 & 0 & 0 & 0 & 0 & $\mathrm{P}$ \\
\hline 5 & $1+\mathrm{f}$ & 0 & 0 & 0 & 0 & 0 & 0 & 0 & 0 & 0 & 0 & 0 & $\mathrm{~N}$ \\
\hline 6 & $4+$ & 0 & 0 & 0 & $2+$ & 0 & 0 & 0 & 0 & 0 & 0 & 0 & $\mathrm{~N}$ \\
\hline 7 & $3+$ & 0 & $1+\mathrm{f}$ & $1+\mathrm{f}$ & $3+$ & 0 & 0 & 0 & $1+\mathrm{f}$ & 0 & 0 & 0 & $\mathrm{P}$ \\
\hline 8 & $1+\mathrm{f}$ & 0 & 0 & 0 & 0 & 0 & 0 & 0 & 0 & 0 & 0 & 0 & $\mathrm{P}$ \\
\hline 9 & $3+\mathrm{f}$ & 0 & 0 & 0 & $2+$ & 0 & 0 & 0 & 0 & 0 & 0 & 0 & $\mathrm{~N}$ \\
\hline 10 & 0 & 0 & 0 & 0 & 0 & 0 & 0 & 0 & 0 & 0 & 0 & 0 & $\mathrm{~N}$ \\
\hline
\end{tabular}

$1+$, rare; $2+$, mild; 3+, moderate; 4+, marked; f, focal; CK, cytokeratin; pCEA, polyclonal carcinoembryonic antigen; * can, canaliculi; AFP, alpha-fetoprotein; EMA, epithelial membrane antigen; CHR, chromogranin; SYN, synaptophysin; Ubiq, ubiquitin; P, present; NP, none present.

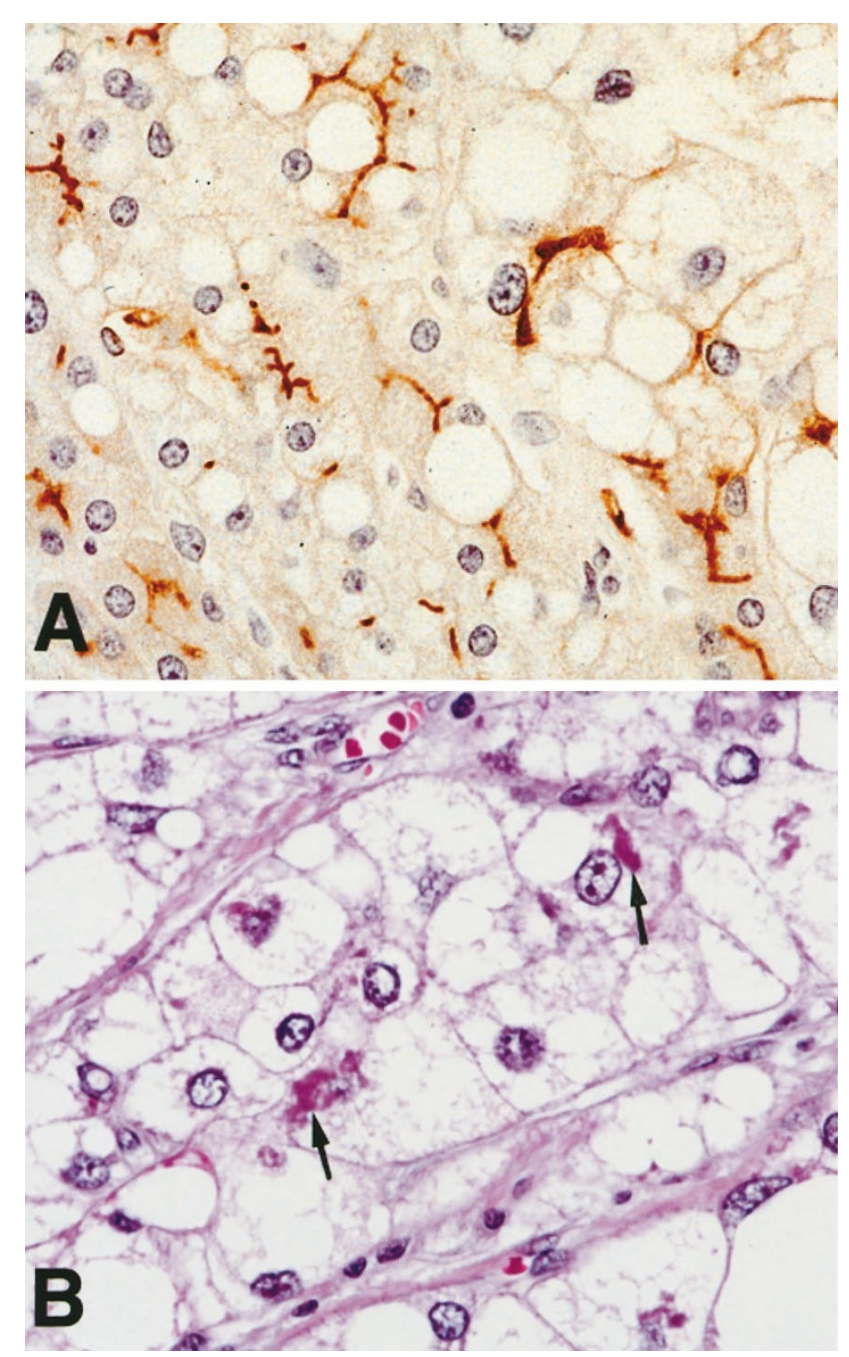

FIGURE 3. Hepatocellular clear cell carcinoma. A, polyclonal carcinoembryonic antigen (immunostain). B, Mallory bodies (arrows) (hematoxylin and eosin stain).

\section{DISCUSSION}

Primary clear cell tumors arise in many organs of the body and all can mimic, RCC-CC histologically (6-18). In our experience, clear cell carcinomas in the liver are either primary or metastatic from the kidney. We therefore chose to focus our study on these two major organs. Our intention was to evaluate the possibility of using the Hepatocyte immunostain (DAKO) as a single tool for diagnosis rather than a panel of costly immunohistochemical stains.

The Hepatocyte monoclonal antibody (Hep Par 1) was developed in 1993 by a group of researchers from the University of Pittsburgh School of Medicine, Pittsburgh, Pennsylvania, and the University of North Carolina at Chapel Hill, North Carolina (1). Their monoclonal antibody, which they named Hepatocyte Paraffin 1 (Hep Par 1), reacted with both normal and neoplastic hepatocytes in routine formalin-fixed, paraffin-embedded tissues. Although the nature of the antigen to which the hepatocyte antibody actually binds is not established, some investigators believe that it binds to liver cell mitochondria (1-3).

Using tissue from a failed allograft liver, the researchers injected a supernatant into six-week-old female mice and fused with myeloma cells. They were able to isolate a single clone (OCH1E5.2.10) that was highly specific for adult and fetal liver, and developed an immunoperoxidase stain using mouse immunoglobulin G (IgG). It produced a distinct, granular cytoplasmic staining of hepatocytes, but failed to react with bile ducts and nonparenchymal cells of the liver. The antibody stained a majority of hepatocellular carcinomas, including the fibrolamellar variant. It failed to react with a wide variety of other malignancies with the exception of focal staining in a few gastrointestinal malignancies, including a subpopulation of gastric carcinomas. In their study, 37 of 38 hepatocellular carcinomas were positive; the one negative tumor was a "sclerosing HCC," which was probably an adenocarcinoma. Two of 35 biliary tract tumors showed only rare positive cells. Three of 10 gastric tumors were positive; all were poorly differentiated signet ring or mixed intestinal/signet ring carcinomas. Only three of 12 pancreatic tumors showed a rare positive cell. Sixteen other tumors from various extrahepatic organs were all negative. 


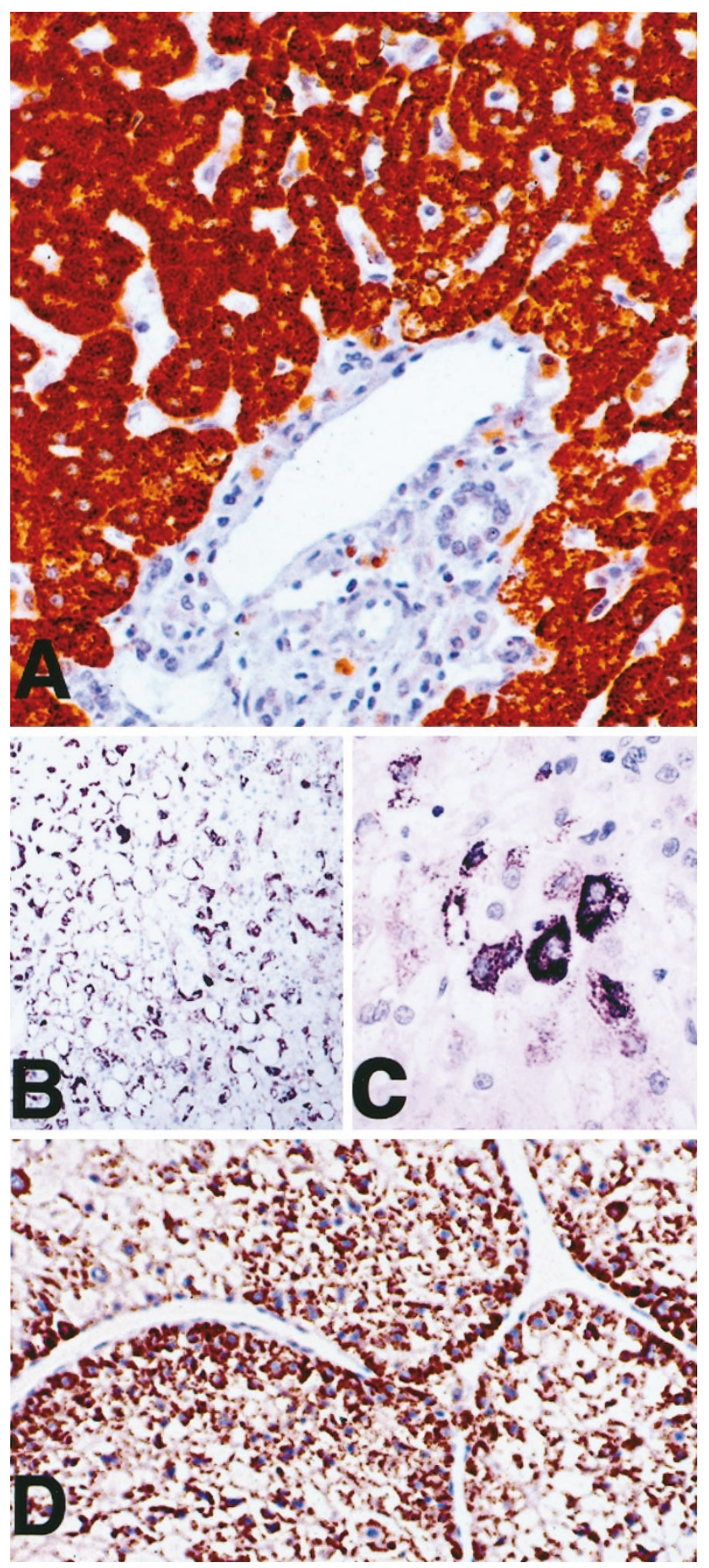

FIGURE 4. Hepatocellular clear cell carcinoma. A, normal nontumor liver around a portal area (Hepatocyte immunostain). B and $\mathbf{C}$, sheets of tumor cells with focal positivity (Hepatocyte immunostain). D, tumor trabeculae with dense positivity (Hepatocyte immunostain).

In 1997, Minervini et al. (2) used Hep Par 1 as part of an antibody panel to differentiate hepatocellular from nonhepatocellular neoplasms (65 liver tumors and two extrahepatic tumors from patients with documented liver tumors). They reported that Hep Par 1 alone had an $82 \%$ sensitivity and $90 \%$ specificity for the detection of hepatocellular neoplasms. Polyclonal CEA (canalicular staining pattern) had a

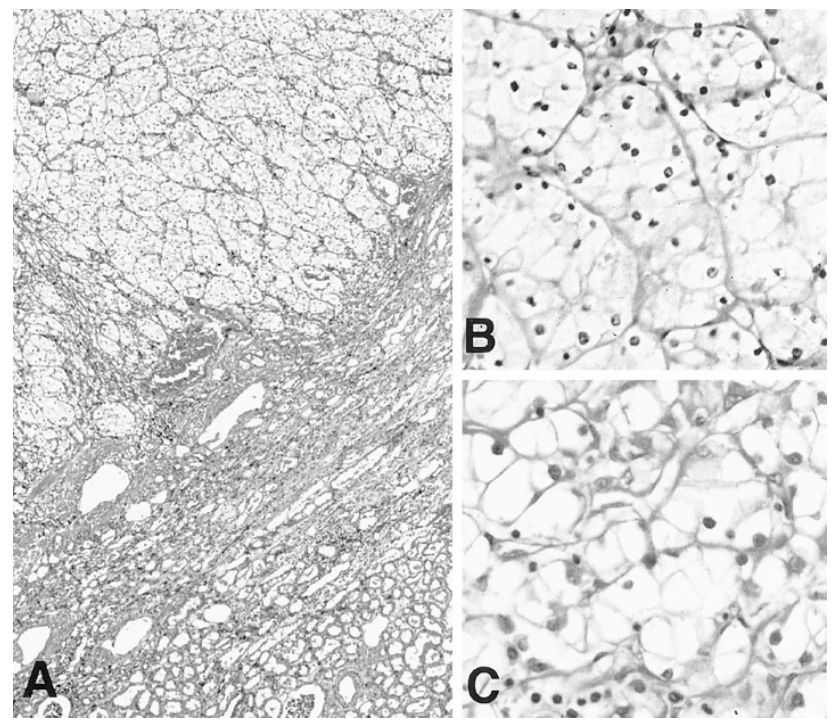

FIGURE 5. Renal clear cell carcinoma. A, low-power view of tumor, capsule and normal nontumor parenchyma. B, high-power view of acinar pattern. C, high-power view of sheets of tumor cells.

sensitivity of $79 \%$ and a specificity of $97 \%$, and alpha-fetoprotein (only positive in $57 \%$ of HCC cases) had a $57 \%$ sensitivity and $97 \%$ specificity.

Fasano et al. (3) evaluated the immunohistochemistry of 12 hepatoblastomas and 27 other childhood tumors. All hepatocyte-derived tumors were immunoreactive with Hep Par 1 (clone OCH1E5.2.10), whereas all other tumors were negative. They concluded that Hep Par 1 and pCEA were the most useful markers in the diagnosis of hepatoblastomas.

Renal clear cell carcinoma can be histologically indistinguishable from HCC-CC $(4,19,20)$. Grossly, both tumors are well demarcated from the surrounding nontumor parenchyma by a complete or partial fibrous capsule and are tan-brown to yellowwhite. Intratumoral fibrosis is rare unless hemorrhage and necrosis had occurred. The cells are round or polygonal in shape, and contain abundant glycogen and/or fat, giving them a water-cell cytoplasm. Ultrastructural studies have shown that the clear cell appearance is due to the combination of sparse organelles and an increased cytoplasmic glycogen and lipid content $(5,21,22)$. Mallory bodies occurred in $40 \%$ of our HCC-CC cases, but none were found in the RCC-CC cases. There is one case report of globular Mallory-like bodies in RCC-CC (23), but this finding has not been confirmed by other reports. In our study, the vascular and reticulin patterns in HCC-CC and RCC-CC were similar.

A histologic diagnosis of HCC-CC is possible if foci of classical HCC (eosinophilic cells arranged in trabeculae and/or pseudoglands), canalicular, or cytoplasmic bile production and Mallory bodies are found, without the need for immunohistochemical stains. The presence of chronic liver disease and/or 
TABLE 4. Immunohistochemical Findings in Renal Clear Cell Carcinomas

\begin{tabular}{|c|c|c|c|c|c|c|c|c|c|c|c|c|c|}
\hline Case & Hepatocyte & Kermix & CK 7 & CK 20 & $\begin{array}{l}\text { pCEA } \\
{ }^{*} \text { can }\end{array}$ & AFP & S-100 & EMA & BER-EP4 & CHR & SYN & $\begin{array}{l}\text { Leu } \\
\text { M-1 }\end{array}$ & Ubiq \\
\hline 1 & 0 & 0 & 0 & 0 & 0 & 0 & 0 & $1+$ & 0 & 0 & 0 & NA & $\mathrm{N}$ \\
\hline 2 & 0 & $3+$ & 0 & 0 & 0 & 0 & 0 & $2+$ & 0 & 0 & 0 & $4+\mathrm{f}$ & $\mathrm{N}$ \\
\hline 3 & 0 & $2+$ & 0 & 0 & 0 & 0 & $1+\mathrm{f}$ & $2+$ & 0 & 0 & 0 & $3+\mathrm{f}$ & $\mathrm{N}$ \\
\hline 4 & 0 & $2+$ & 0 & 0 & 0 & 0 & $1+\mathrm{f}$ & $3+$ & $1+$ & 0 & 0 & $3+\mathrm{f}$ & $\mathrm{N}$ \\
\hline 5 & 0 & $1+$ & 0 & 0 & 0 & 0 & 0 & 0 & 0 & 0 & 0 & NA & $\mathrm{N}$ \\
\hline 6 & 0 & $1+$ & 0 & 0 & 0 & 0 & $1+\mathrm{f}$ & $2+$ & 0 & 0 & 0 & $3+\mathrm{f}$ & $\mathrm{N}$ \\
\hline 7 & 0 & $1+$ & 0 & 0 & 0 & 0 & 0 & $1+$ & 0 & 0 & 0 & $4+\mathrm{f}$ & $\mathrm{N}$ \\
\hline 8 & 0 & $3+$ & 0 & 0 & 0 & 0 & 0 & $3+$ & 0 & 0 & 0 & NA & $\mathrm{N}$ \\
\hline 9 & 0 & $3+$ & 0 & 0 & 0 & 0 & $1+\mathrm{f}$ & $3+$ & $1+$ & 0 & 0 & $3+\mathrm{f}$ & $\mathrm{N}$ \\
\hline 10 & 0 & $3+$ & 0 & 0 & 0 & 0 & 0 & $2+$ & 0 & 0 & 0 & $3+\mathrm{f}$ & $\mathrm{N}$ \\
\hline
\end{tabular}

$1+$, rare; $2+$, mild; $3+$, moderate; $4+$, marked; f, focal; CK, cytokeratin; pCEA, polyclonal carcinoembryonic antigen; * can, canaliculi; AFP, alpha-fetoprotein; EMA, epithelial membrane antigen; CHR, chromogranin; SYN, synaptophysin; Ubiq, ubiquitin; NA, not available; N, none present.

cirrhosis in nontumor parenchyma may favor HCC but, in seven of our cases, there was no cirrhosis (24-27).

In small liver biopsies, or in cases where the diagnostic histological features of HCC are not found in a HCC-CC, immunohistochemical studies are necessary (Tables 3 and 4). The most useful stains for distinguishing HCC-CC from RCC$\mathrm{CC}$, are the Hepatocyte immunostain (DAKO) (sensitivity, 90\%) and pCEA (sensitivity, 60\%), and because these also have a specificity of $100 \%$, they would usually be negative in all RCC-CC. Using similar criteria, we found that Leu $\mathrm{M}-1$, EMA, and pancytokeratin were the next most useful immunostains because they were always negative in HCC-CC and almost always positive in RCC-CC. Although normally negative in HCC-CC, pancytokeratin under certain circumstances may show aberrant antigen expression in diseased states making it somewhat less useful than Leu M-1 and EMA. Table 5 shows specificity and sensitivity of Hepatocyte immunostaining (Hep Par 1). Based on this table, its positive and negative predictive values were $100 \%$ and $91 \%$, respectively. None of the tumors were reactive with the alpha-fetoprotein immunostain, but we have found this to be the case in any HCC unless the serum level is elevated. Furthermore, in addition to liver and germ cell tumors, positive AFPs have been described in a few intestinal adenocarcinomas as well as in female genital tract tumors (17, 20).

An immunohistochemical study of RCC from Japan included 21 cases of RCC-CC (28). The results of their panel of immunohistochemical stains were similar to ours with positive EMA in 13 cases, pancytokeratin (AE1/AE3) in 10 cases, CK 18 in 16 cases, Leu $\mathrm{M}-1$ in 10 cases, CK 7 in three cases, CK 8 in seven cases, and CK 19 in six cases.

A clear cell variant of intrahepatic cholangiocarcinoma is extremely rare, but a case was recently reported by Tihan et al. (29). The tumor showed both papillary and clear cell features; was focally

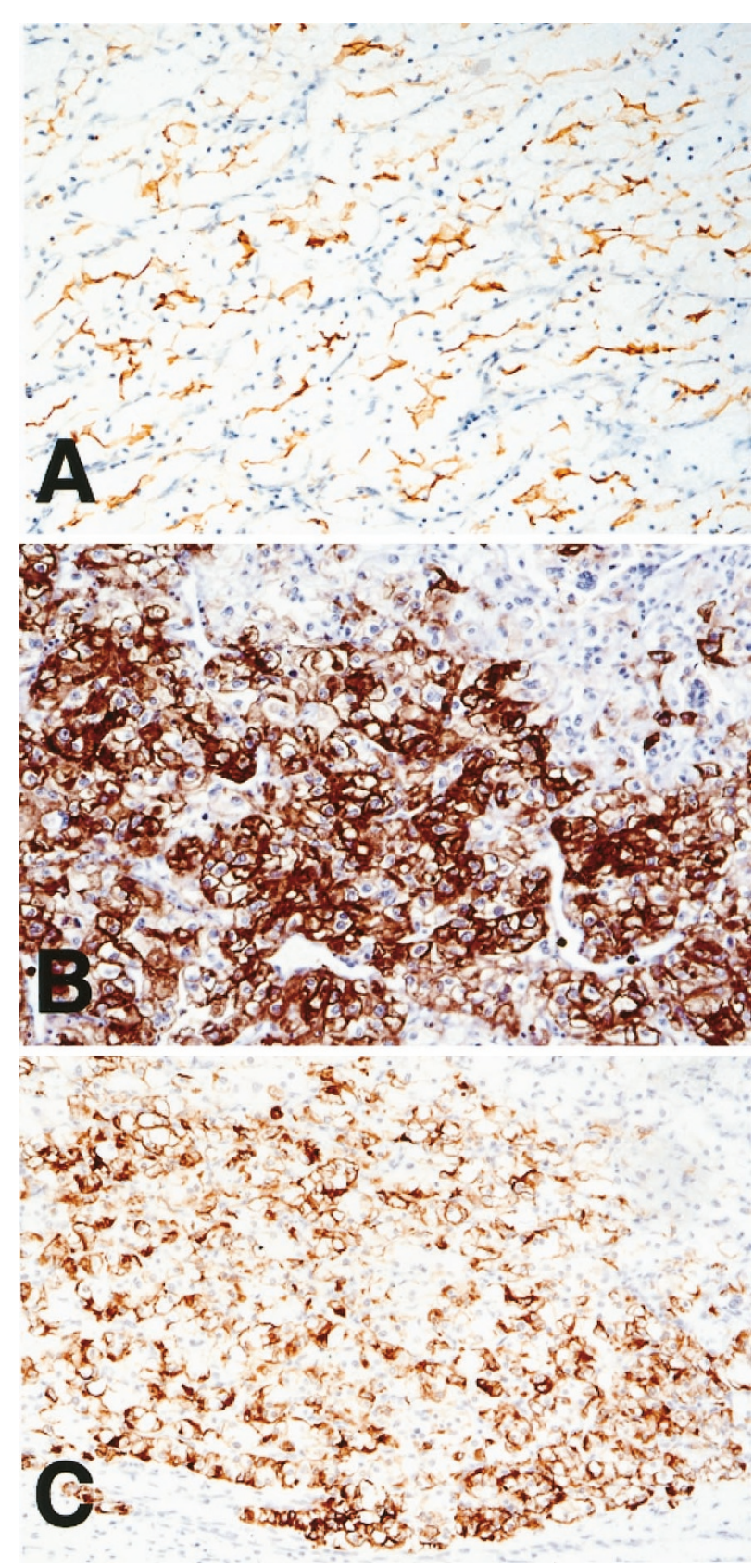

FIGURE 6. Renal clear cell carcinoma. A, epithelial membrane antigen, immunostain. B, Leu M-1, immunostain. C, pancytokeratin (Kermix), immunostain. 
TABLE 5. Results of Hepatocyte Immunostaining of Hepatocellular and Renal Clear Cell Carcinomas

\begin{tabular}{lccc}
\hline \multirow{2}{*}{$\begin{array}{c}\text { Hepatocyte } \\
\text { Stain* }\end{array}$} & \multicolumn{3}{c}{ Tumor Type } \\
\cline { 2 - 4 } & HCC-CC & RCC-CC & Total \\
\hline Positive & 9 & 0 & 9 \\
Negative & 1 & 10 & 11 \\
Total & 10 & 10 & 20 \\
\hline
\end{tabular}

* Sensitivity $90 \%$; specificity $100 \%$.

TABLE 6. Comparison of Hepatocyte Immunostaining of Hepatocellular Clear Cell Carcinoma and All Other NonHepatocellular Clear Cell Neoplasms

\begin{tabular}{lccc}
\hline \multirow{2}{*}{$\begin{array}{c}\text { Hepatocyte } \\
\text { Stain* }\end{array}$} & \multicolumn{3}{c}{ Tumor Type } \\
\cline { 2 - 4 } & HCC-CC & RCC-CC & Total \\
\hline Positive & 9 & 0 & 9 \\
Negative & 1 & 21 & 22 \\
Total & 10 & 21 & 31
\end{tabular}

* Sensitivity $90 \%$; specificity $100 \%$.

Non HCC-CC, non-HCC clear cell neoplasms (includes renal, salivary gland, lung, thyroid, ovary, and urinary bladder).

positive for mucicarmine; had diffuse, strong immunoreactivity with AE1, CK 7, CK 19, and Cam 5.2; focal reactivity with epithelial membrane antigen; and was negative with CK 20. Primary clear cell cholangiocarcinomas should therefore be included in the differential diagnosis of clear cell epithelial tumors in the liver that are negative with the Hepatocyte antibody (DAKO) and positive for epithelial markers.

In summary, the diagnosis of HCC-CC can easily be made when ample tissue is available (wedge biopsies or autopsy material). Immunohistochemical stains are unnecessary when definitive foci of classical trabecular HCC with canaliculi, bile production and Mallory bodies, are present. But in small needle biopsies, or when these features are not present, immunohistochemical stains should be performed to differentiate HCC-CC, which appears to have a better prognosis than nonclear cell HCC, from metastatic clear cell tumors, which are known to have a poor prognosis $(21,25)$. We recommend the Hepatocyte antibody (DAKO) as a screening immunostain in working-up a clear cell tumor in the liver when diagnostic histologic criteria of HCC are absent. In this setting, Hepatocyte immunostaining (DAKO) distinguishes clear cell HCC-CC from other clear cell malignancies with a sensitivity of $90 \%$ and specificity of $100 \%$ when adequate material is available (Tables 5 and 6). If negative, then other immunostains such as PCEA, ubiquitin, EMA, Kermix, and Leu M-1 can be performed and evaluated. With elevated serum levels of alpha-fetoprotein, the chances of finding positive cells on immunostain are good and would support the diagnosis (4). If a kidney mass is present, a positive EMA and Leu M-1 would support a renal primary and exclude HCC-CC (28), but in the ab- sence of a renal mass, other clear cell tumors that can express some of the same epithelial antigens (i.e. salivary gland, ovary, thyroid, lung, bile ducts, urogenital) should be considered in the differential diagnosis.

\section{REFERENCES}

1. Wennerberg AE, Nalesnik MA, Coleman WB. Hepatocyte paraffin 1: a monoclonal antibody that reacts with hepatocytes and can be used for differential diagnosis of hepatic tumors. Am J Pathol 1993;143:1050-4.

2. Minervini MI, Demetris AJ, Lee RG, Carr BI, Madariaga J, Nalesnik MA. Utilization of hepatocyte-specific antibody in the immunocytochemical evaluation of liver tumors. Mod Pathol 1997;10:686-92.

3. Fasano M, Theise ND, Nalesnik M, Goswami S, Garcia de Davila MT, Finegold MJ, et al. Immunohistochemical evaluation of hepatoblastomas with use of the hepatocyte-specific marker, hepatocyte paraffin 1 , and the polyclonal anticarcinoembryonic antigen. Mod Pathol 1998;11:934-8.

4. Adamek HE, Spiethoff A, Kaufmann V, Jakobs R, Riemann JF. Primary clear cell carcinoma of noncirrhotic liver: immunohistochemical discrimination of hepatocellular and cholangiocellular origin. Dig Dis Sci 1998;43:33-8.

5. Ericsson JLE, Seljelid R, Orrenius S. Comparative light and electron microscopic observations of the cytoplasmic matrix in renal carcinomas. Virchows Arch Pathol Anat Physiol Klin Med 1966;341:204-23.

6. Ellis GL. "Clear cell" oncocytoma of salivary gland. Hum Pathol 1988;19:862-7.

7. Hasserjian RP, Klimstra DS, Rosai J. Carcinoma of the thymus with clear-cell features. Am J Surg Pathol 1995;19:83541.

8. Hayes MMM, Seidman JD, Ashton MA. Glycogen-rich clear cell carcinoma of the breast. Am J Surg Pathol 1995;19:90411.

9. Malpica A, Tornos C, Burke TW, Silva EG. Low-stage clearcell carcinoma of the endometrium. Am J Surg Pathol 1995; 19:769-74.

10. Vardaman C, Albores-Saavedra J. Clear cell carcinomas of the gallbladder and extrahepatic bile ducts. Am J Surg Pathol 1995;19:91-9.

11. Zorludemir S, Scheithauer BW, Hirose T, Houten CV, Miller G, Meyer FB. Clear cell meningioma. A clinicopathologic study of a potentially aggressive variant of meningioma. Am J Surg Pathol 1995;19:493-505.

12. Yang SH, Watanabe J, Nakashima O, Kojiro M. Clinicopathologic study on clear cell hepatocellular carcinoma. Pathol Int 1996;46:503-9.

13. Wick MR, Ritter JH, Humphrey PA, Nappi O. Clear cell neoplasms of the endocrine system and thymus. Sem Diagn Pathol 1997;14:183-202.

14. Maiorano E, Altini M, Dent M, Favia G. Clear cell tumors of the salivary glands, jaws, and oral mucosa. Sem Diagn Pathol 1997;14:203-12.

15. Dina R, Eusebi V. Clear cell tumors of the breast. Sem Diagn Pathol 1997;14:175-82.

16. Ellis GL. Clear cell neoplasms in salivary glands: Clearly a diagnostic challenge. Ann Diagn Pathol 1998;2:61-78.

17. Young RH, Hart WR. Metastatic intestinal carcinomas simulating primary ovarian clear cell carcinoma and secretory endometrioid carcinoma. Am J Surg Pathol 1998;22:805-15.

18. Albores-Saavedra J, Molberg K, Henson DE. Unusual malignant epithelial tumors of the gallbladder. Sem Diagn Pathol 1996;13:326-38

19. Nappi O, Mills SE, Swanson PE, Wick MR. Clear cell tumors 
of unknown nature and origin: a systematic approach to diagnosis. Sem Diagn Pathol 1997;14:164-74.

20. Ritter JH, Mills SE, Gaffey MJ, Nappi O, Wick MR. Clear cell tumors of the alimentary tract and abdominal cavity. Sem Diagn Pathol 1997;14:213-9.

21. Wu PC, Lai CL, Lam KG, Lok ASF, Lin HJ. Clear cell carcinoma of liver. An ultrastructural study. Cancer 1983;52:504-7.

22. Kwon TJ, Ro JY, Mackay B. Clear cell carcinoma: an ultrastructural study of 57 tumors from various sites. Ultrastruct Pathol 1996;20:519-27.

23. Jagirdar J, Irie T, French SW, Patil J, Schwarz R, Paronetto F. Globular Mallory-like bodies in renal cell carcinoma: report of a case and review of cytoplasmic eosinophilic globules. Hum Pathol 1985;16:949-52.

24. Nzeako UC, Goodman ZD, Ishak KG. Hepatocellular carcinoma in cirrhotic and noncirrhotic livers. A clinico- histopathologic study of 304 North American patients. Am J Clin Pathol 1996;105:65-75.

25. Lai CL, Wu PC, Lam KC, Todd D. Histologic prognostic indicators in hepatocellular carcinoma. Cancer 1979;44:1677-83.

26. Lai CL, Lam KC, Wong KP, Wu PC, Todd D. Clinical features of hepatocellular carcinoma: review of 211 patients in Hong Kong. Cancer 1981;47:2746-55.

27. Buchanan TF, Huvos AG. Clear-cell carcinoma of the liver. A clinicopathologic study of 13 patients. Am J Clin Pathol 1974;61:529-39.

28. Taki A, Nakatani Y, Misugi K, Yao M, Nagashima Y. Chromophobe renal cell carcinoma: an immunohistochemical study of 21 Japanese cases. Mod Pathol 1999;12:310-7.

29. Tihan T, Blumgart L, Klimstra DS. Clear cell papillary carcinoma of the liver: an unusual variant of peripheral cholangiocarcinoma. Hum Pathol 1998;29:196-200. 